\title{
A vida dos jovens no Projeto Jaíba: um estudo de representações a partir de memes
}

\author{
Angelina Moreira Melo' \\ Nathália Thaís Cosmo da Silva² \\ Sheila Maria Doula ${ }^{3}$
}

\section{Resumo}

Este artigo analisa as representações sobre a vida dos jovens no Projeto Jaíba - maior projeto público de irrigação da América Latina - por meio de memes publicados nas páginas do Facebook "Jaíba Mil Crau" e "South Projeto Jaíba Memes". O corpus desse estudo é composto por 31 memes, que foram categorizados a partir da análise de conteúdo e interpretados com base na teoria das representações sociais. Os resultados indicam que a representação da vida dos jovens está ancorada em uma crítica social, nos âmbitos da formação profissional, da sociabilidade, da constituição familiar e da vulnerabilidade social.

\section{Palavras-Chave}

Juventude rural, Representações Sociais, Memes, Projeto Jaíba.

The life of young people in the Jaíba Project: a study of representations from memes

\begin{abstract}
This article analyzes the representations about the lives of young people in the Jaíba Project - the largest public irrigation project in Latin America - based on memes published on the Facebook pages "Jaíba Mil Grau" and "South Projeto Jaíba Memes". The corpus of this study consists of 31 memes, which were categorized based on content analysis and interpreted by using the theory of social representations. The results indicate that the representation of young people's lives is anchored in a social critique, in the areas of professional training, sociability, family constitution and social vulnerability.
\end{abstract}

\section{Keywords}

Rural Youth, Social Representations, Memes, Jaíba Project. 


\section{Introdução}

O Projeto Jaíba está localizado na região Sudeste do Brasil, no Norte do estado de Minas Gerais, à margem direita do Rio São Francisco, nos municípios de Jaíba e Matias Cardoso. Esse empreendimento corresponde ao maior projeto público de irrigação em linha contínua da América Latina, que começou a ser construído a partir da década de 1970 (SEAPA, 2005). Os objetivos eram i) promover o crescimento econômico e o desenvolvimento regional do Norte de Minas Gerais; ii) conter os fluxos migratórios e as tensões na urbanização; e iii) suprir a crescente necessidade de produção de alimentos para abastecimento interno e possivel produção de excedentes para exportação (BARBOSA, 2013).

Para a implementação do empreendimento houve a mobilização de investimentos governamentais nas esferas Federal, Estadual e Municipal. A construção da infraestrutura visava irrigar uma área total de 100 mil hectares, com foco agrícola na fruticultura, que seria introduzida na região a partir de empresas agroindustriais (CODEVASF, 2018). No entanto, para concluir a primeira etapa de construção do projeto, foi necessário o subsídio de empréstimos que vieram do Banco Mundial que, ao entrar em cena na história do Projeto Jaíba, propôs que ele tivesse um caráter social - o que acabou se concretizando em 1985, com a criação de assentamentos destinados a agricultores familiares (SOARES, 1999; SEAPA, 2005).

O Projeto Jaíba foi projetado para ser implementado em quatro etapas. Em linhas gerais, a etapa I foi destinada, majoritariamente, aos agricultores familiares, e atualmente é administrada pela Companhia de Desenvolvimento dos Vales do São Francisco e do Parnaíba (Codevasf). A etapa II foi designada, exclusivamente, para os empreendimentos rurais particulares e é administrada pelo Governo do Estado de Minas Gerais. As etapas III e IV ainda não foram concluídas, mas serão destinadas aos empreendimentos rurais particulares (SEAPA, 2005, CODEVAF, 2018). 
Os agricultores familiares que fazem parte do Projeto Jaíba foram selecionados com base em critérios propostos pelo Banco Mundial, que se referem principalmente à vulnerabilidade socioeconômica e à aptidão para a agricultura comercial (MOURA, 2014). As famílias selecionadas receberam lotes de cinco hectares com terras férteis e a infraestrutura de irrigação pronta para ser utilizada (SOARES, 1999). Porém, para a produção agrícola e reprodução dessas famílias dependia-se de acesso a crédito e assistência técnica e social, conforme se pode identificar nas pesquisas feitas sobre o Projeto Jaíba.

As pesquisas realizadas junto aos agricultores familiares, assentados na etapa I, apontam para uma série de dificuldades enfrentadas ao longo dos anos, como a vulnerabilidade socioeconômica - representada, principalmente, pela dificuldade de arcar com os custos da produção irrigada, a falta de crédito e assistência social (SOARES, 1999; SILVA, 2001; MARTINS, 2008; MOURA, 2014); o endividamento rural - causado por linhas de crédito rígidas, que eram destinadas apenas para o desenvolvimento da bananicultura, o que resultou na queda dos preços devido à elevada oferta e pouca demanda (FILHO, 2003; SILVA, 2006; FELÍCIO, 2018); o conflito ambiental - gerado pela criação das áreas de preservação a partir da desapropriação de povos tradicionais (ANAYA, 2012); e a desigualdade de gênero identificada por meio da invisibilização do trabalho das mulheres em relação ao dos homens (BARBOSA, 2013).

Como evidenciado, as pesquisas analisaram dimensões que contemplam a vida das famílias. No entanto, não foram identificadas investigações acerca de segmentos sociais específicos, como os jovens do Projeto Jaíba. Ao analisar as pesquisas nacionais sobre o tema da juventude rural, Weisheimer (2005) identificou que entre o período de 1990 a 2004 foi produzido um total de cinquenta trabalhos (entre dissertações, teses, livros e artigos). Em estudo mais recente, Troian e Breitenbach (2018) apontam que as pesquisas brasileiras sobre essa temática focam nas questões de sucessão familiar e migração ru- 
ral-urbana. Isso indica que essa área de pesquisa ainda carece de múltiplos olhares sobre a vida do jovem no âmbito rural, como se pretende neste trabalho.

Um aspecto importante nas pesquisas sobre os jovens refere-se a sua diversidade, o que permite, em estudos recentes, abordar esse segmento como "juventudes" (CASTRO, 2009). O mesmo fenômeno ocorre no meio rural devido à sua heterogeneidade, o que aponta também a pluralidade das vivências da juventude nas "ruralidades" (CARNEIRO, 2008). Dessa maneira, a mobilização da temática da juventude no meio rural precisa partir da perspectiva dos diferentes contextos, campos de possibilidades e dilemas que compõem o cenário do rural investigado e de seus jovens.

Outro aspecto importante a ser considerado é o que se entende por juventude, haja vista que a definição de seu conceito não é consensual entre os teóricos da área. Weisheimer (2005) analisou a mobilização do conceito de juventude rural na literatura e identificou cinco abordagens: faixa etária; ciclo da vida; geração; cultura ou modo de vida e representação social ou autorrepresentação. O autor ainda aponta para três formas de utilização dessas definições: a ênfase em uma única abordagem, a combinação entre mais de uma abordagem e os que não se preocupam em apresentar uma definição por compreender a temática como autoexplicativa (WEISHEIMER, 2005).

A compreensão de juventude que será abordada neste artigo vai ao encontro da perspectiva de vários autores, entre eles Bourdieu (1983), que entende a categoria juventude como uma construção social que se demarca em meio a relações de disputa e poder. Toma-se também como base o entendimento de Carneiro (1998), que identifica o jovem de sua pesquisa como o indivíduo que se encontra entre os seus projetos de vida e os caminhos para a sua realização. E a concepção de Castro (2009), que apresenta o jovem rural a partir de uma categoria social e política que está na busca por maior espaço de ação e de acesso a direitos, condições de vida e trabalho. 
Em face do exposto, acredita-se que os jovens do Projeto Jaíba são atores sociais que vivenciam um determinado espaço rural para além da agricultura irrigada. Esses atores estão inseridos no convívio das comunidades, em suas áreas de lazer e cultura, no trabalho, nas escolas, no âmbito subjetivo dos anseios e projetos para o futuro - estão, enfim, inseridos em várias esferas do cotidiano que podem ser utilizadas para compreender suas vidas no Projeto Jaíba. Além dessas relações intracomunitárias, os jovens do Projeto Jaíba, como parte das juventudes rurais na atualidade, ampliam e viabilizam seus contatos e interações comunicacionais por meio da internet. Mais especificamente as mídias sociais (Instagram, Twitter e Facebook $)^{4}$, sendo que a apropriação desse recurso não ocorre apenas no âmbito urbano, mas também no rural, principalmente por meio dos jovens (SILVA, 2019).

Nas redes sociais, informações sobre o Projeto Jaíba podem ser encontradas, por exemplo, em vídeos no Youtube e páginas do Facebook. Em uma exploração realizada no Facebook, foi possível encontrar duas páginas que publicam memes sobre a vida no Projeto Jaíba: "Jaíba Mil Crau" e "South Projeto Jaíba Memes". A partir do cenário apresentado, o objetivo desse artigo é analisar as representações sobre a vida dos jovens no Projeto Jaíba a partir de memes publicados nessas páginas.

\section{A teoria das representações sociais e a categoria jovens rurais}

Uma maneira de interpretar e analisar como as pessoas conferem sentido à realidade é pela lente teórica das representações sociais. Essa teoria parte de um conhecimento prático que dá sentido aos acontecimentos do cotidiano e contribui na construção social da realidade. Toda representação social vai ser a representação de alguma coisa ou de alguém, a partir de uma elaboração cognitiva e simbólica (SÊCA, 2000).

Émile Durkheim foi o precursor do conceito de representações coletivas, elaborado a partir de sua compreensão sobre a "ideação coletiva”, com base nas produções mentais associadas a objetos e práticas 
sociais. Tal conceito serviu de base para Serge Moscovici, responsável por aperfeiçoá-lo para o que hoje se conhece como representações sociais (JODELET, 2001). Moscovici (1985) partiu de uma perspectiva crítica, focado na maneira como os seres humanos tentam captar e compreender a realidade que os rodeia.

$\mathrm{Na}$ atualidade, na condição de uma das principais autoras responsável pelo aprofundamento e exposição da teoria, Denise Jodelet caracteriza as representações sociais como "uma forma de conhecimento, socialmente elaborado e compartilhado, que tem um objetivo prático e concorre para a construção de uma realidade comum a um conjunto social" (JODELET, 2001, p. 4-5). Portanto, pode-se afirmar que a representação está intimamente relacionada com a comunicação, com a interação social e com a forma de expressar os pensamentos, haja vista que a representação se converte em um instrumento que permite a comunicação em uma mesma linguagem (SÊCA, 2000).

Dentre os aspectos dos processos representativos, destaca-se aqui a ancoragem, pois é ela que assegura a incorporação social da representação - "a ancoragem enraíza a representação e seu objeto em uma rede de significações que permite situá-las face aos valores sociais e dar-Ihes coerência" (JODELET, 2001, p. 18). Tem-se também o imaginário, que é uma expressão do pensamento que se evidencia por imagens e discursos a fim de definir uma realidade, que não é expressa de forma literal. Isso envolve a relação entre significantes (imagens, palavras) com seus significados (representações, significações) (PESAVENTO, 1995).

Nesse sentido, Pesavento (1995, p. 16) afırma que "o imaginário, enquanto representação, revela um sentido ou envolve uma significação para além do aparente". Isso implica pensar de forma alegórica, na qual se aponta para uma coisa, mas busca-se outra, em um sentido para além do explicitado (PESAVENTO, 1995). No caso deste artigo, utilizar essa lente teórica para análise dos memes significa enxergá-los como uma imagem alegórica, que utiliza da jocosidade como um elemento fundamental de seu conteúdo. No entanto, considera-se que o seu con- 
teúdo possui uma conotação para além do riso, que se ancora em uma crítica social, a partir da experiência no cotidiano do Projeto Jaíba.

Nessa perspectiva, assim como Pesavento (1995), assume-se a premissa de que só é possível elucidar a representação a partir da articulação texto/contexto. Por esse motivo, o conteúdo da mensagem dos memes é contrastado com a realidade, a partir de dados socioeconômicos e estudos precedentes. O acesso ao contexto é o que dá sentido à representação, é uma fonte de signifıcância que precisa ser descrita e analisada (PESAVENTO, 1995). Ressalta-se que aqui será seguida a orientação de Pesavento (1998) de não julgar a representação nem buscar a sua veracidade, mas sim compreendê-la "a partir de sua força, pelo seu grau de aceitação, socialização e capacidade mobilizadora" (PESAVENTO, 1998, p. 55).

No que se refere à categoria juventude rural, pode-se observar que ela é objeto de diferentes representações, que hora se aproximam, hora se distanciam entre si. Ao realizar uma investigação sobre a produção acadêmica do período entre 1999 e 2004, Weisheimer (2005) aponta que os estudos se pautaram em definir juventude rural como um processo transitório da condição social de dependência plena na infância à plena independência na idade adulta. Nessa transição mobiliza-se uma série de papéis sociais que assinalam a condição juvenil com vistas a garantir a reprodução, a continuidade ou a ruptura social (WEISHEIMER, 2005).

Em estudos posteriores, verifica-se que as representações sociais dos jovens rurais estão ancoradas nas representações sociais da sociedade urbanizada (WHITAKER; ONOFRE, 2006). Nessa perspectiva, o imaginário dos jovens rurais é povoado por uma visão negativa de sua condição de vida (sem acesso ao estudo, à profissionalização, ao trabalho, ao lazer e à cultura) o que reproduz o estigma dominante de que o rural é o lugar do "não-desenvolvimento", do atraso e do arcaico (SIFUENTES, 2009; CASTRO, 2009; PAULO, 2010; BIASUS; BRANCO, 2013; DOS ANJOS; CALDAS, 2015). 
Mais recentemente, ao contrário de estudos anteriores, aponta-se para uma representação positiva sobre o rural, principalmente por parte dos jovens, que entendem esse espaço como palco de transformações, o que abre novas perspectivas e campos de possibilidades para o estudo, o desenvolvimento de atividades não agrícolas e a comunicação. (CARVALHO; COSTA, 2020; BELAU; ROCHA, 2020).

\section{A emergência e importância dos memes}

O termo "meme" foi cunhado pela primeira vez pelo biólogo Richard Dawkins em seu livro "O Gene Egoísta” (1976). Dawkins afırma que "um 'meme de ideia' pode ser definido como uma entidade capaz de ser transmitida de um cérebro para outro". (DAWKINS, 2001, p. 217). Para Dawkins, o "meme" seria a unidade de evolução cultural humana, o meme é o "gene" da cultura que se reproduz por meio de seus replicadores - as pessoas (RECUERO, 2018). Contudo, mesmo que os memes necessitem dos seres humanos para se replicar, eles vivem para além da consciência de determinado indivíduo, portanto, podem ser compreendidos como signos, providos de vida própria que se perpetuam mediante a cultura por meio de repetições e/ou alterações (FRICO, 2017).

Na hipótese de Frigo (2017), os memes podem configurar um tipo de linguagem que não possui regras preestabelecidas, mas que por meio da repetição e padronização tornam-se conhecidas. A partir desse entendimento, compreende-se que a construção de um meme ocorre a partir da ressignificação de imagens, vídeos e textos, que se constituem em uma forma singular de expressar uma releitura da realidade (RECUERO, 2009). Um ambiente prolífero para a disseminação dos memes são as redes sociais - com foco neste artigo para o Facebook. $\mathrm{Na}$ perspectiva de Recuero (2009), a disseminação do meme pode ocorrer em nível local ou global, a depender do contexto retratado.

No caso dos memes sobre o Projeto Jaíba, acredita-se que eles são replicados em nível local e possuem sentido e significado para as pessoas que vivenciam o ambiente retratado. Ressalta-se que não foram 
encontrados estudos que analisam memes com base nas representações sociais sobre jovens no contexto do rural, o que aponta para a relevância deste artigo que se propõe a realizar essa discussão. Além disso, é importante salientar a necessidade de se compreender os novos códigos comunicativos entre os jovens no meio rural, como sinalizadores de demandas e críticas sociais.

\section{Metodologia}

Os memes foram coletados de forma manual nas páginas do Facebook “Jaíba Mil Grau” (criada em 10 de outubro de 2016) e "South Projeto Jaíba Memes" (criada em 08 de março de 2018), que são as únicas que publicam memes sobre o Projeto Jaíba e por esse motivo foram escolhidas como fonte dos dados. Foram coletados todos os memes sobre o Projeto Jaíba (total 86) publicados desde a criação das páginas até a última publicação (março de 2020 nas duas páginas).

Após essa etapa, realizou-se uma leitura para selecionar os memes de interesse desse artigo (que retratam a vida dos jovens), o que resultou em um corpus de 31 memes. A análise foi realizada a partir da proposta de Recuero (2018), que é a análise de dados de mídia social (neste artigo são os memes) a partir da análise de conteúdo de Bardin (1977). Segundo Recuero (2018), o primeiro passo para utilizar essa técnica é separar as unidades de análise dentro dos dados recolhidos, sendo que nos memes foram escolhidas as partes textuais como unidades de análise, mas sem desconsiderar o contexto retratado pelas imagens, que em alguns memes são fundamentais para a interpretação e análise.

Para o próximo passo, foram realizados recortes no conteúdo das mensagens, que foram reunidos em categorias temáticas constituídas por palavras e/ou expressões que revelam a ideia central da mensagem (LAVILLE; DIONE, 1999). Esse procedimento foi realizado em três etapas: i) pré-análise e exploração - os memes foram coletados e selecionados com base no objetivo deste artigo; ii) codificação - clas- 
sifıcação inicial dos memes e identificação de categorias mais amplas e, por fım; iii) a criação de um conjunto de temas/categorias (ou conceitos) - que compõem os resultados da pesquisa (BARDIN, 1977). Tal procedimento resultou na identificação de várias temáticas que contemplam diversos aspectos da vida dos jovens no Projeto Jaíba e que são apresentados nos tópicos seguintes.

\section{Resultados e discussão}

A apresentação dos resultados se fará a partir das temáticas unificadoras, que englobam os temas e subtemas identificados no percurso metodológico e contemplam a representação da vida dos jovens no Projeto Jaíba.

Quadro 1: Temáticas unificadoras para apresentação dos resultados

\begin{tabular}{lllc}
\hline $\begin{array}{l}\text { Temáticas } \\
\text { Unificadoras }\end{array}$ & Temas & Subtemas & $\begin{array}{c}\text { Total de } \\
\text { memes }\end{array}$ \\
\hline $\begin{array}{l}\text { Formação } \\
\text { Profissional }\end{array}$ & Trabalho & $\begin{array}{l}\text { Opções de trabalho } \\
\text { Trabalho Familiar }\end{array}$ & 14 \\
\hline Sociabilidade & Educação & $\begin{array}{l}\text { Falta de incentivo ao } \\
\text { estudo }\end{array}$ & 07 \\
\hline Constituição & Relações & Ausência de espaços de & \\
Familiar & sociabilidade & 06 \\
& $\begin{array}{l}\text { Sucessão } \\
\text { familiar }\end{array}$ & agricultor & Trabalho rural \\
\hline
\end{tabular}

Fonte: elaboração própria

O quadro 1 apresenta as temáticas unificadoras - formação profissional; constituição familiar; sociabilidade e insegurança. A partir delas 
os resultados deste artigo serão apresentados e analisados com base na teoria das representações sociais, em dados socioeconômicos e pesquisas acadêmicas precedentes.

\section{“Você não vai precisar carregar banana se souber embalar": formação profissional}

A temática unificadora da "formação profissional" possui o total de 14 memes, dispostos em dois subtemas. O primeiro é o "trabalho", composto por nove memes, sendo que sete deles remetem à ideia de que só há duas opções de trabalho para os jovens - carregar banana ou embalar -, o que aponta para a mesma finalidade: o trabalho rural. Outros memes indicam que os jovens realizam atividades para a família, que estão relacionadas com o trabalho rural (Figuras 1 e 2).

Figuras 1 e 2: subtema "trabalho"
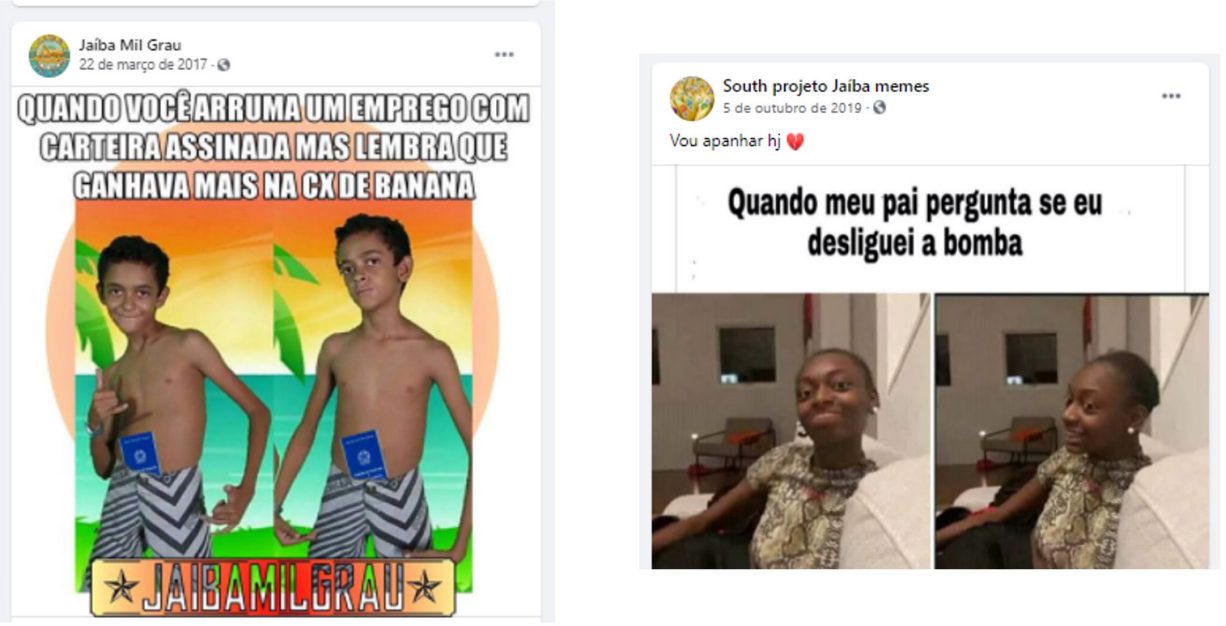

Fonte: Jaíba Mil Grau (2017); South Projeto Jaíba Memes (2019).

Os memes indicam que a formação profissional dos jovens está centrada no trabalho rural. Ao averiguar a taxa de ocupação nos municípios que compõem o Projeto Jaíba, pode-se verificar que a taxa de ocupados no setor agropecuário (tabela 1) é muito maior (nos dois 
municípios) em relação a outros setores, que foram contemplados apenas para efeito de comparação.

Tabela 1: Porcentagem de ocupação para os municípios de Jaíba e Matias Cardoso

\begin{tabular}{cccc}
\hline Territorialidades & $\begin{array}{c}\text { \% dos ocupados no } \\
\text { setor agropecuário } \\
2010\end{array}$ & $\begin{array}{c}\text { \% dos ocupados no } \\
\text { setor de serviços } \\
\mathbf{2 0 1 0}\end{array}$ & $\begin{array}{c}\text { \% dos ocupados } \\
\text { no setor comércio } \\
\mathbf{2 0 1 0}\end{array}$ \\
\hline Brasil & 13,55 & 44,29 & 15,38 \\
\hline Jaíba & 45,00 & 26,4 & 10,48 \\
\hline Matias Cardoso & 46,95 & 30,34 & 6,19 \\
\hline
\end{tabular}

Fontes: dados do IBGE (2020) e de registros administrativos, conforme especificados nos metadados disponíveis em: http://atlasbrasil.org.br/acervo/biblioteca.

Os dados da ocupação no setor agropecuário indicam que há uma convergência com as informações dos memes, no sentido de que a representação da vida dos jovens, na dimensão profissional, está focalizada no âmbito rural. Além disso, um aspecto importante a ser considerado é que as opções de trabalho apresentadas - carregar banana ou embalar - se referem a empregos simbolicamente avaliados como de "segunda classe", que não necessitam de especialização técnica e/ou formação profissional.

Dessa maneira, é identificado também na literatura que a falta de opções de trabalho para os jovens é um fator recorrente no meio rural (CASTRO, 2009; BIASUS; BRANCO, 2013; DOS ANJOS; CALDAS, 2015). Segundo Carneiro (1998), os jovens não encontram no espaço rural o incentivo para o desenvolvimento da profissionalização, nem a oportunidade de atividades laborais financeiramente promissoras.

No que se refere ao segundo subtema, tem-se a "educação", sobre o qual os memes (Figuras 3 e 4) apresentam um cenário onde não há incentivo para os estudos, pois os jovens rurais são inseridos no mundo do trabalho mais cedo, geralmente ainda na infância. 
Figuras 3 e 4: subtema "educação"
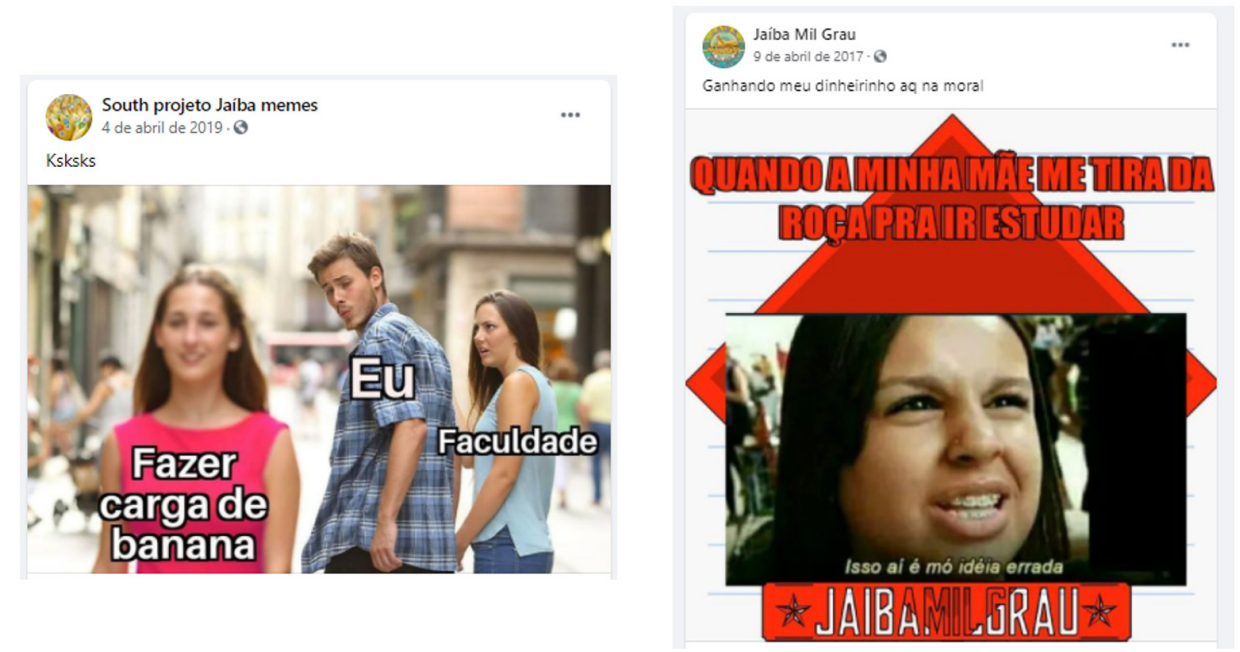

Fonte: South Projeto Jaíba Memes (2019); Jaíba Mil Grau (2017).

Ressalta-se que a visão estereotipada sobre a preferência dos jovens rurais pelo trabalho em detrimento do estudo faz parte de uma construção histórica do imaginário social que atribui ao rural o signo do atraso. $\mathrm{Na}$ interpretação dos memes, no entanto, o trabalho gera renda ao passo que o estudo é um investimento (econômico e social) que, em muitos casos, as famílias agricultoras não têm condições de arcar e que teria que ser realizado nas cidades, o que resultaria na saída desses jovens do espaço rural e na incerteza do retorno após a conclusão do curso.

Além disso, pode-se identificar na pesquisa de Silva (2001) que as escolas do Projeto Jaíba apresentam uma série de precariedades, como a escassez de recursos físicos (telefone, televisão, vídeo, transporte para os alunos, mesas e cadeiras) e humanos (professores da área de história e geografia). Tais fatores podem contribuir para que os jovens se sintam desmotivados com o estudo e que o ensino superior seja representado nos memes como um projeto distante de suas vidas.

Segundo Carneiro (1998), os jovens rurais vivem uma dicotomia entre a dedicação aos estudos como uma condição para "ser alguém na 
vida" e a permanência na atividade agrícola como uma alternativa mais viável. Entre as duas opções há uma série de fatores que interferem na tomada de decisão dos jovens, sendo que o contexto socioeconômico familiar e as oportunidades disponíveis são de extrema importância para os jovens definirem as suas escolhas.

\section{"Aqui não tem shopping e nem cinema": sociabilidade}

A categoria sociabilidade é composta por sete memes relacionados ao "lazer", sendo que seis deles apontam para a ausência de espaços com essa função, especificamente, à falta de shopping, cinema, pontos turísticos, teatro, museu, biblioteca e parques (Figuras 5 e 6). Um meme remete à ideia de que passar férias no Projeto Jaíba se associa com a execução de tarefas laborais.

Figuras 5 e 6: subtema "lazer"
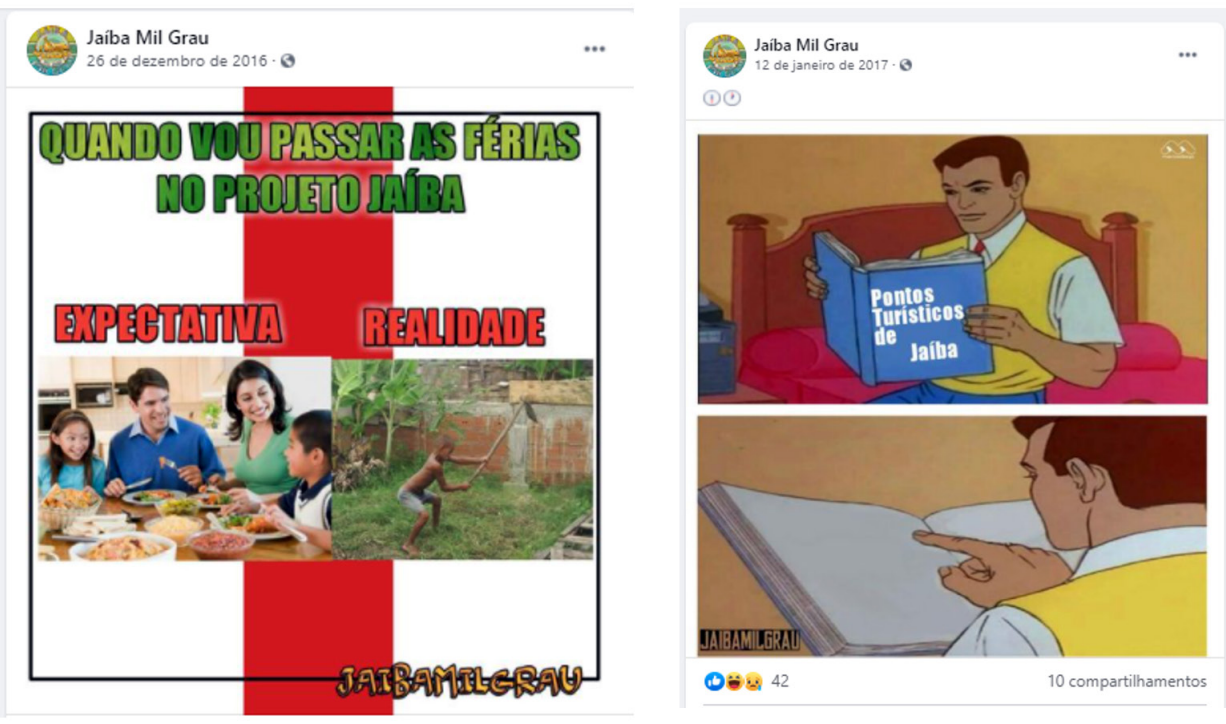

Fonte: Jaíba Mil Grau (2016; 2017).

Em similaridade com o fato apresentado pelos memes, os autores Sifuentes (2009), Castro (2009), Dos Anjos e Caldas (2015) apontam que é 
inerente aos espaços rurais a ausência de locais de lazer, principalmente aqueles similares ao urbano (shopping, cinema, teatro e museu). Na pesquisa realizada por Sifuentes (2009, p. 8), a autora aponta que, de maneira geral, o dia a dia dos jovens rurais que estudam costuma ser constituído pelas seguintes atividades: "acordam cedo para ir à escola (entre $5 \mathrm{~h}$ e $6 \mathrm{~h}$ se estudam na cidade), passam a manhã na escola, realizam atividades em casa ou na lavoura à tarde e à noite fazem tarefas da escola e assistem televisão". Ao que tudo indica, o tempo dos jovens disponível para o lazer é curto e está associado ao entretenimento promovido pela televisão.

Nesse sentido, pode-se questionar se há uma relação entre a ausência de espaços e infraestrutura para a oferta de atividades culturais tipicamente urbanas ao estigma do rural como local de atraso, e em que medida essa relação pode contribuir para a migração dos jovens para os grandes centros urbanos. No entanto, como descatam alguns estudos, as necessidades dos jovem (sejam eles rurais ou urbanos) são similares, todos demandam por ter acesso à cultura, ao lazer e ao entretenimento (DOS ANJOS; CALDAS, 2015).

\section{“Me chamou pra sair, mas não é agricultor": constituição familiar}

A temática da constituição familiar é composta por seis memes, sendo que quatro deles se referem às relações amorosas. Esses memes apresentam relações heterossexuais, na qual um determinado tipo de agricultor é o motivo de aspiração das mulheres, ou seja, aquele que é retratado como alguém que possui "hectares de banana" ou "planta banana”, o que confere uma conotação de empresário rural. Pode-se observar que esse sujeito é diferente dos que são apresentados nos memes da temática da "Formação Profissional", que possuem como alternativas de trabalho somente carregar banana ou embalar. Portanto, os memes sobre as relações amorosas representam as muIheres como sujeitos que desejam se relacionar com os que possuem os meios de produção - com os donos das terras. Em certa medida, isso também representa um anseio por "mudar de vida” (Figura 7). 
Os outros dois memes são do subtema da sucessão familiar e expõem um contexto onde o pai representa o personagem que atribui ao filho a responsabilidade de continuação do trabalho rural da família (plantar banana). No meme em questão (Figura 8), utiliza-se da jocosidade ao apresentar um recém nascido que nega a trasmissão geracional da atividade e o resultado desssa ruptura é o filho sendo deixado para a adoção.

Figuras 7 e 8: subtemas "relações amorosas" e "sucessão familiar"
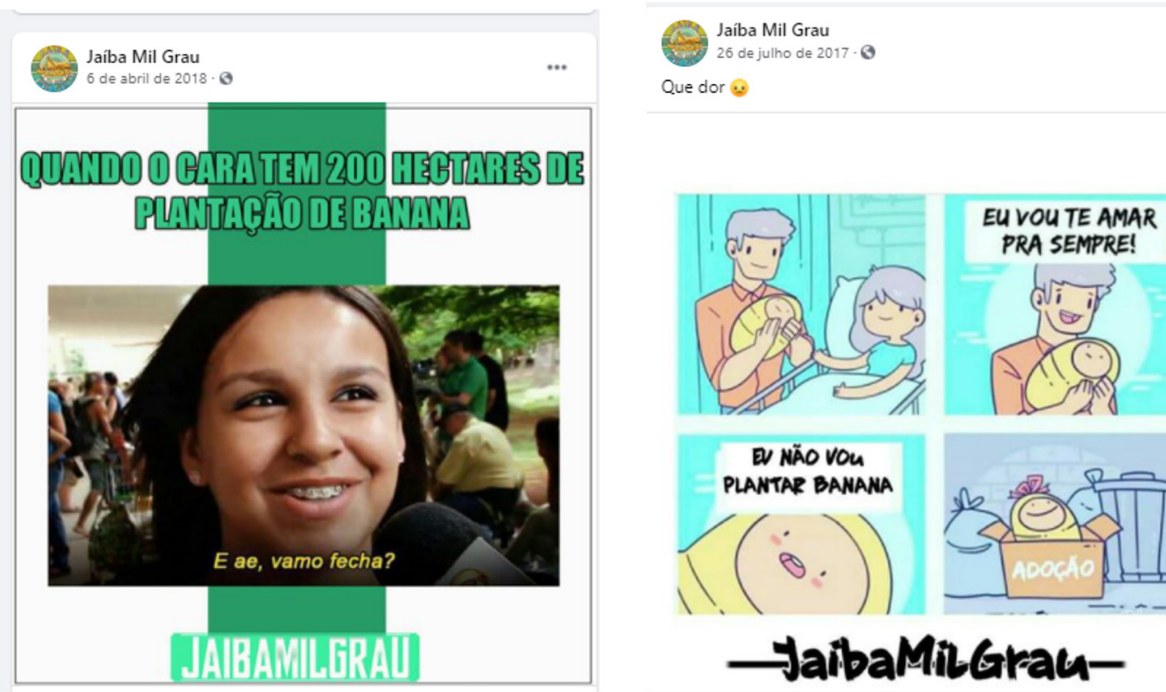

PRA SEMPRE!
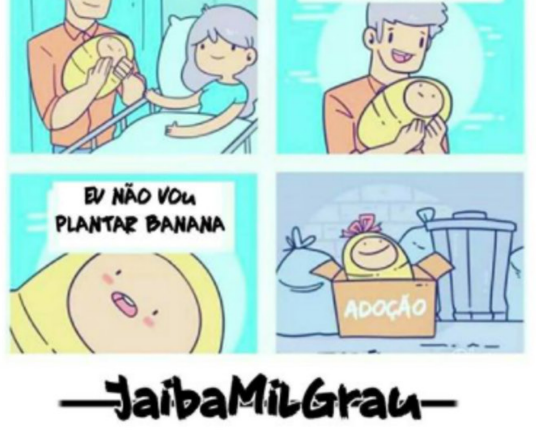

Fonte: Jaíba Mil Grau (2017; 2018).

Conforme aponta Castro (2009), o tema da sucessão familiar já é bastante discutido na literatura, principalmente no que concerne aos jovens rurais, que são considerados os responsáveis por perpetuar a atividade agrícola, haja vista que a aderência a essa atividade por pessoas sem vivência familiar nessa área é pouco frequente. Isso gera uma expectativa quanto à permanencia dos jovens no meio rural, como uma forma de garantir a reprodução da família, da produção agrícola e da propriedade rural (CASTRO, 2009). 
Em sua pesquisa, Carneiro (1998) identificou que há uma relação entre o trabalho rural e a continuidade dos estudos pois, geralmente, o filho escolhido para a sucessão familiar é aquele considerado com "falta de aptidão para o estudo". Tal fator pode contribuir para reforçar no imaginário popular a ideia de que a permânencia no meio rural está associada à falta de estudo e ao atraso.

Na pesquisa realizada pela Paulo (2010), pode-se idenficar que os jovens rurais possuem uma representação positiva da profissão dos pais na agricultura, na qual identificam o trabalho como indicador de dignidade. No entanto, no ambiente escolar onde há a presença de alunos dos espaços rurais e urbanos, os jovens rurais apresentam dificuldade em assumir (e deixar transparecer) que executam atividades no cotidiano da propriedade rural fimiliar. A autora aponta que o estigma do rural como local de atraso e a visão do agricultor como um sujeito ignorante e que realiza atividades sujas, fazem com que os jovens rurais assumam um sentimento de vergonha diante do "outro" (os urbanos).

A vergonha que esses jovens sentem está relacionada com a internalização de valores culturais de que o "outro" os considera inferiores, devido às condições de trabalho que vivenciam. O sentimento de vergonha, nesse contexto, está imbricado em relações de poder, produzidas pelas representações sobre profissões mais e menos valorizadas socialmente e que conferem status diferenciado aos profissionais (PAULO, 2010).

Já na pesquisa reallizada pela Castro (2009), pode-se verificar a incidência de estudos que apontam para a necessidade da criação de políticas públicas direcionadas para a juventude rural, com base em um projeto educacional que valorize o rural e prepare os jovens para se desenvolverem como agricultores. Há que se questionar se com tais investimentos, será possível que os estigmas identificados sejam modificados. Por fim, no que concerne à permanencia de jovens no espaço rural, acredita-se que estes precisam ter seus direitos garantidos 
e efetivados (acesso à terra, ao estudo, ao lazer, à cultura, ao trabalho, entre outros) como condição de ampliar os campos de possibilidades nos quais os projetos de vida possam se concretizar, mesmo que isso signifique seguir um caminho diferente daquele proposto pela família.

\section{“Assalto no Projeto Jaíba não é novidade": sobre a insegurança derivada da vulnerabilidade Social}

A última temática refere-se à insegurança que é derivada da vulnerabilidade social, composta pelo subtema violência que ocorre em três cenários - ruas (02 memes), escolas (01) e festas (01). No âmbito das ruas, os memes veiculam a mensagem de que elas não são um local seguro, pois "não é novidade que um assalto tenha ocorrido". A violência nas escolas e nas festas é simbolizada pelo mesmo objeto - o colete à prova de balas -, considerado como item de uso obrigatório nesses dois ambientes (Figuras 09 e 10).

Figuras 09 e 10: subtema violência
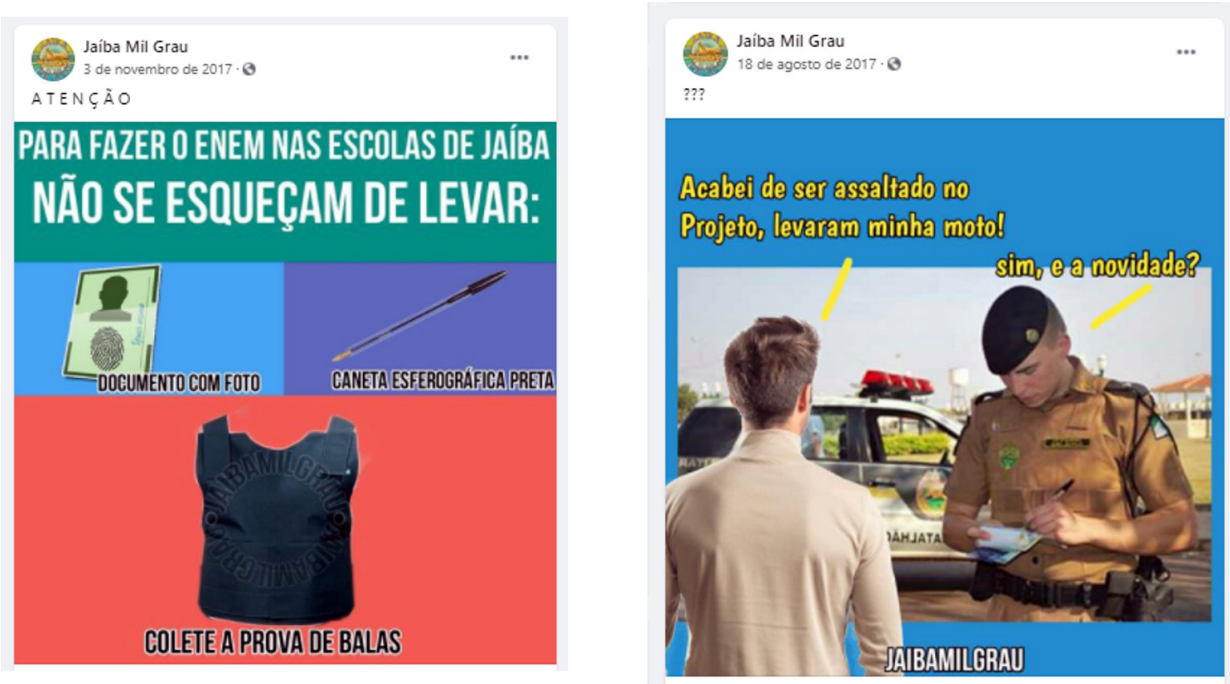

Fonte: Jaíba Mil Grau (2017).

Os locais aos quais se associam os memes que remetem à violência são os ambientes tipicamente frequentado por jovens (escola, 
festas e ruas), o que resulta em uma imagem da vida marcada pela violência, que afeta várias esferas da sociabilidade. Como identificado em tópicos anteriores, já que os memes apontam que não há motivação dos jovens pelo estudo, deve-se questionar em que medida a violência nas escolas pode contribuir para tal desestímulo.

As pesquisas realizadas no Projeto Jaíba não apontam para dados e/ou informações sobre a violência/criminalidade. Contudo, um fator bastante recorrente que pode ser identificado são alguns indicadores de vulnerabilidade socioeconômica e pobreza. Sendo assim, no cenário da agricultura familiar no Projeto Jaíba, Sacramento (2003) e Silva (2006) identificam que cerca de 40\% dos agricultores se encontram no limiar da linha de pobreza, outros estão com um alto nível de endividamento e a falta de acesso a crédito é uma condição habitual por parte significativa dos agricultores. Diante do que foi identificado nas pesquisas, buscou-se verificar a porcentagem de inscritos no Programa Social Bolsa Família (Tabela 2), que é destinado às famílias de baixa renda.

Tabela 2: Porcentagem de participantes no Bolsa Família

\begin{tabular}{cc}
\hline Territorialidades & $\begin{array}{c}\text { \% de pessoas inscritas no Cadastro Único que } \\
\text { recebem Bolsa Família (2017) }\end{array}$ \\
\hline Brasil & $66,12 \%$ \\
\hline Jaíba & $86,66 \%$ \\
\hline Matias Cardoso & $65,92 \%$ \\
\hline
\end{tabular}

Fontes: dados do IBGE (2020) e de registros administrativos, conforme especificados nos metadados disponíveis em: http://atlasbrasil.org.br/acervo/biblioteca.

Os dados apontam para uma alta porcentagem de participantes no programa, inclusive maior nos municípios que integram o Projeto Jaíba do que a nível nacional. No que se refere aos indicadores de renda e pobreza, os dados mostram que houve um aumento na renda e diminuição da pobreza (Tabela 3). 
Tabela 3: indicadores de renda e pobreza

\begin{tabular}{ccccccc}
\hline Territorialidades & $\begin{array}{c}\text { IDHM } \\
\text { Renda } \\
1991\end{array}$ & $\begin{array}{c}\text { IDHM } \\
\text { Renda } \\
\mathbf{2 0 1 0}\end{array}$ & $\begin{array}{c}\text { \% de } \\
\text { pobres } \\
1991\end{array}$ & $\begin{array}{c}\text { \% de } \\
\text { pobres } \\
\mathbf{2 0 1 0}\end{array}$ & $\begin{array}{c}\text { \% de } \\
\text { extremamente } \\
\text { pobres 1991 }\end{array}$ & $\begin{array}{c}\text { \% de } \\
\text { extremamente } \\
\text { pobres 2010 }\end{array}$ \\
\hline Brasil & 0,647 & 0,739 & 38,16 & 15,2 & 18,64 & 6,62 \\
\hline Jaíba & 0,45 & 0,619 & 67,63 & 20,28 & 39,05 & 6,79 \\
\hline Matias Cardoso & 0,407 & 0,584 & 81,06 & 39,94 & 49,86 & 16,66 \\
\hline
\end{tabular}

Fontes: dados do IBGE (2020) e de registros administrativos, conforme especificados nos metadados disponíveis em: http://atlasbrasil.org.br/acervo/biblioteca.

Acredita-se que a implementação do Projeto Jaíba pode ter contri-

buído para a elevação do indicador de renda e a diminuição da porcentagem de pobreza. Contudo, a pobreza não foi erradicada e a porcentagem de participantes em programa social é alta. Dessa maneira, há que se questionar se esses dados se relacionam com a incidência da violência e em que medida isso afeta a vida dos jovens.

Por fim, de maneira geral, os aspectos identificados neste estudo sobre a vida dos jovens no Projeto Jaíba vai ao encontro de outras pesquisas, como a realizada por Paulo (2010), na qual os jovens representam o meio rural como um espaço de ausências, o que resulta na percepção das vulnerabilidades a que estão expostos e que contribui para a identificação com outros setores de juventudes, como a juventude das periferias urbanas, que sofrem das mesmas carências. Daí a relevância dos memes como forma de representação e de comunicação, pois seus significados são inteligíveis e compartilhados por um público mais amplo, extrapolando uma visão meramente local da vivência juvenil.

\section{Considerações finais}

Ao analisar as representações da vida dos jovens no Projeto Jaíba a partir da publicação de memes nas páginas do Facebook "Jaíba Mil Crau" e "South Projeto Jaíba Memes", se observa uma série de ancoragens em críticas sociais com base na experiência no cotidiano dos 
jovens: trabalho; lazer; ensino superior; relações amorosas; violência e sucessão familiar. Esses temas foram agrupados em quatro temáticas da representação: i) formação profissional; ii) sociabilidade; iii) constituição familiar; e iv) insegurança.

A formação profissional é uma temática que evidencia a falta de incentivo ao ensino superior, a imersão dos jovens em tarefas/trabaIhos no âmbito rural familiar e as opções de trabalho se caracterizam como subempregos, o que contribui para reforçar o estigma do rural como local de atraso, que não incentiva a formação profissional de seus jovens. Na temática da sociabilidade os memes apontam para a ausência de espaços de lazer, como cinema, shopping, teatro, biblioteca, praças, entre outros. De maneira geral, esses locais fazem parte da representação dos centros urbanos e são marcadores de diferenças entre o rural e o urbano, no qual o rural segue representado como locus de não reprodução de determinadas liberdades de lazer.

A constituiçao familiar mostra relações amorosas heterossexuais, na qual o agricultor, que possui hectares de banana, é o objeto de desejo das mulheres. A sucessão familiar também faz parte dessa temática e evidencia que os filhos dos agricultores não possuem ou não valorizam outra opção a não ser seguir os passos da família na agricultura. Por fim, a insegurança mostra a violência como condição habitual na vida dos jovens, que a ela estão expostos em escolas, festas e ruas, ou seja, nos espaços privilegiados da sociabilidade juvenil.

Portanto, este estudo aponta que as representações sobre a vida no Projeto Jaíba estão ancoradas em uma experiência concreta que permite aos jovens que ali residem e trabalham problematizar, refletir e construir uma crítica social sobre as ausências e consequentes vulnerabilidades. Dessa maneira, os memes aqui analisados, justamente por utilizarem elementos de jocosidade, indicam uma ressignificação do real expressa em imagens e textos que, em seu conjunto, constroem o que Pesavento (1995) chama de imagem alegórica, pois além de proporcionar o riso (e o rir de si mesmo), também possibilita a reflexão 
crítica - e ambos, o humor e a reflexividade, fundados na experiência do cotidiano, acabam por representar a própria vida.

\section{Agradecimento}

O presente trabalho foi realizado com apoio da Coordenação de Aperfeiçoamento de Pessoal de Nível Superior - Brasil (CAPES) - Código de Financiamento 001.

\section{Referências}

ANAYA, Felisa Cançado. De "Encurralados pelos Parques" a "Vazanteiros em Movimento": as reivindicações territoriais das comunidades vazanteiras de Pau Preto, Pau de Légua e Quilombo da Lapinha no Campo Ambiental. Tese (Doutorado em Filosofia). Universidade Federal de Minas Gerais, Belo Horizonte, p. 255. 2012. Disponivel em: http://hdl.handle.net/1843/BUOS-97KHGE. Acesso em: 20 dez. 2020.

BARDIN, L. Análise de conteúdo. Lisboa: Edições 70, 1977.

BARBOSA, Ana Alves Neta. Mulheres na Agricultura Familiar do Semiárido Norte-Mineiro: Divisão Social do Trabalho e Gênero no Projeto Jaíba. Tese (Doutorado em Desenvolvimento Rural). Universidade Federal do Rio Grande do Sul, Porto Alegre, p. 223. 2013. Disponível em: http://hdl.handle. net/10183/79131. Acesso em: 20 dez. 2020.

BELAU; Joelton da Silva1; ROCHA, Ana Georgina Peixoto. Jovens Rurais do Recôncavo da Bahia: Porque ir para a cidade? Cadernos de Agroecologia. v. 15, no 2, 2020. Disponível em: http://cadernos.aba-agroecologia.org.br/index. php/cadernos/article/view/5952/2922. Acesso em: 17 jan. 2021.

BIASUS, F.; BRANCO, S. Representação social de meio urbano e meio rural de jovens residentes no meio rural. Revista Perspectiva, p. 27-37, 2013. Disponivel em: http://www.uricer.edu.br/site/pdfs/perspectiva/140_370.pdf. Acesso em 17 jan. 2021.

BOURDIEU, Pierre. Questões de Sociologia. Rio de Janeiro: Editora Marco Zero Limitada, 1983.

CARNEIRO, Maria José. O ideal rurbano: campo e cidade no imaginário de jovens rurais. Mundo rural e política: ensaios interdisciplinares. Rio de Janeiro: Campus, p. 95-118, 1998. 
CASTRO, Elisa Guaraná de. Juventude rural no Brasil: processos de exclusão e a construção de um ator político. Revista latinoamericana de ciências Sociales, Niñez y juventud, v. 7, n. 1, p. 179-208, 2009. Disponível em: http://www.scielo.org.co/scielo.php?script=sci_arttext\&pid=S1692715X2009000100008\&l$\mathrm{ng}=$ en\&nrm=iso. Acesso em 10 dez. 2020.

CARVALHO, Géssika Cecília; COSTA, Maria Eduarda Lino da. Social representations of young people in rural settlements in the Zona da Mata of Alagoas. Research, Society and Development. v. 9, n. 10, p. e7439109088, 2020. DOI: 10.33448/rsd-v9i10.9088. Disponivel em: https://www.rsdjournal.org/index. php/rsd/article/view/9088. Acesso em: 17 jan. 2021.

CODEVASF. Companhia de Desenvolvimento dos Vales do São Francisco e do Paranaíba. Avaliação global e sistematização dos aspectos socieconômicos e ambientais do projeto jaíba: Etapa I. Belo Horizonte. 2018. Disponivel em: https:// www.codevasf.gov.br/linhas-de-negocio/irrigacao/projetos-publicos-de-irrigacao/elenco-de-projetos/em-implantacao/jaiba-mg. Acesso em: 26 nov. 2020.

DAWKINS, Richard. O Gene Egoísta. (1979) Coleção O Homem e a Ciência, volume 7. Belo Horizonte: Ed. Itatiaia, 2001.

DOS ANJOS, F. S.; CALDAS, N. V. Ser ou não ser agricultor? Eis a questão. Representações sociais sobre a profissão de agricultor entre jovens de comunidade rural do Sul do Brasil. Revista de Extensão e Estudos Rurais, [S. I.], v. 4, n. 1, 2015. DOI: 10.36363/rever412015\%p. Disponível em: https://periodicos. ufv.br/rever/article/view/3303. Acesso em: 17 jan. 2021.

FELíCIO, Adâmara Santos Gonçalves. Projeto Jaíba Etapa I: análise do processo de concentração da terra em um perímetro irrigado. Dissertação (Mestrado em Desenvolvimento Econômico). Universidade Estadual De Campinas, Campinas, p. 162. 2018. Disponivel em: http://repositorio.unicamp.br/ jspui/handle/REPOSIP/331758. Acesso em 15 out. 2020.

FILHO, Lamartine Sacramento. Rentabilidade e risco da pequena produção de banana no Projeto Jaíba. Tese (Doutorado em Economia Aplicada). Universidade Federal de Viçosa, Viçosa, p. 86. 2003. Disponível em: https://locus.ufv.br//handle/123456789/8985. Acesso em: 20 nov. 2020.

FRICO, Renato Georgette. Política, Memes e o Facebook no Brasil: em busca da ciberdemocracia. Dissertação (Mestrado em Ciências Humanas e Sociais Aplicadas). Faculdade de Ciências Aplicadas da Universidade Estadual de Campinas. Limeira - São Paulo, p. 108. 2017. Disponível em: http://repositorio. unicamp.br/jspui/handle/REPOSIP/325350. Acesso em: 15 de out. de 2020. 
JAÍBA MIL GRAU. Página do Facebook. Criada em: 10 out. 2016. Disponível em: https://www.facebook.com/jaibamilgrau/?ref=page_internal. Acesso em: 15 out. 2020 .

JODELET, Denise. Representações sociais: um domínio em expansão. As representações sociais. Rio de Janeiro: EdUERJ, 2001. p. 17- 44.

KAPLAN, Andreas M.; HAENLEIN, Michael. Users of the world, unite! The challenges and opportunities of social media. Business Horizons, Bloomington, v. 53, n. 1, p. 59-68, 2010. Disponivel em: https://doi.org/10.1016/j. bushor.2009.09.003. Acesso em: 25 nov. 2020.

LAVILLE, Christian.; DIONNE, Jean. A construção do saber: manual de metodologia da pesquisa em ciências humanas. Belo Horizonte: UFMG, 1999.

MARTINS, Simone. Análise da implementação da política nacional de irrigação no Norte de Minas Gerias: o caso do projeto Jaíba. Dissertação (Mestrado em Administração). Universidade Federal de Viçosa, Viçosa, p. 199. 2008. Disponível em: https://locus.ufv.br//handle/123456789/1916. Acesso em: 20 out. 2020.

MOSCOVICI, Serge et al. Psicología social, Influencia e cambios de atitudes: individuos y grupos. 1985.

MOURA, Auricharme Cardoso de. Trajetórias, Memórias e Experiências dos trabalhadores Rurais do Projeto Jaíba-MG. Dissertação (Mestrado em História). Universidade Federal de Uberlândia, Uberlândia, p. 163. 2014. Disponivel em: https://repositorio.ufu.br/handle/123456789/16472. Acesso em: 09 out. 2020.

PAULO, Maria de Assunção Lima de. As contribuições das identidades de jovens rurais na relação com o meio urbano em um pequeno município. Tese (doutorado em Sociologia). Universidade Federal de Pernambuco, p. 259. 2010. Disponível em: https://repositorio.ufpe.br/bitstream/123456789/9589/1/arquivo635_1.pdf. Acesso em: 01 mar. 2021.

PESAVENTO, Sandra. Em busca de uma outra história: imaginando o imaginário. Revista Brasileira de História, São Paulo, v. 15, no 29, 1995. Disponível em: http://www.anpuh.org/revistabrasileira/view?ID_REVISTA_BRASILEI$\mathrm{RA}=14$. Acesso em: 19 nov. 2020.

PESAVENTO, Sandra. Catarina come gente. Imaginário - USP, n. 4, p. 48-58, 1998.

RECUERO, Raquel. Redes sociais na internet. Sulina, 2009. 
RECUERO, Raquel. Estudando Discursos em Mídia Social: Uma Proposta Metodológica. In: Estudando cultura e comunicação com mídias sociais. Organizado por Tarcízio Silva, Jaqueline Buckstegge, Pedro Rogedo. Brasília; IBPAD. 400 p. 2018.

SEAPA - SECRETARIA DE ESTADO, AGRICULTURA, AGROPECUÁRIA E ABASTECIMENTO (Governo de Minas Gerais). Relatório do Projeto Jaíba (20052010). Belo Horizonte, 2005. Disponível em: http://www.agricultura.mg.gov. br/files/jaiba.pdf. Acesso em: 15 out. 2020.

SÊCA, Rafael Augustus. O conceito de representação social nas obras de Denise Jodelet e Serge Moscovici. Anos 90, v. 8, n. 13, 2000.

SIFUENTES, Lírian. A recepção televisiva por jovens rurais: Um estudo sobre as representações do campo e da cidade. In: Congresso de Ciências da Comunicação na Região Sul. p. 1-15. Disponível em: http://www.intercom.org.br/papers/regionais/sul2009/resumos/R16-0270-1.pdf. Acesso em: 17 jan. 2021.

SILVA, Rosilene Maria de Castro. Efeitos distributivos de projetos de irrigação: o caso do projeto Jaíba. Tese (Doutorado em Economia Aplicada). Universidade Federal de Viçosa, Viçosa, p. 89. 2001. Disponível em: https://locus.ufv.br//handle/123456789/8914. Acesso em 10 out. 2020.

SILVA, Amanda Cristina da. Dilemas da agricultura familiar irrigada no Projeto Jaíba, MC. Dissertação (Mestrado em Extensão Rural). Universidade Federal de Viçosa, Viçosa, p. 89. 2006. Disponível em: http://locus.ufv.br/handle/123456789/4204. Acesso em: 10 nov. 2020.

SILVA, Jonathan Fagundes da. Juventude Rural e Telefone Celular: Consumo, Apropriação e Sociabilidade. Dissertação (Mestrado em Extensão Rural). Universidade Federal de Viçosa, Viçosa, p. 95. 2019. https://locus.ufv.br// handle/123456789/26434. Acesso em: 10 nov. 2020.

SOARES, Cecília Cristina. O caráter social e as perspectivas de adaptação da pequena produção inserida em projetos de concepção técnica: o caso do Projeto Jaíba. Dissertação (Mestrado em Administração Rural). Universidade Federal de Lavras, Minas Gerais, p. 144. 1999. Disponível em: http:// repositorio.ufla.br/jspui/handle/1/10400. Acesso em: 25 out. 2020.

SOUTH PROJETO JAÍBA MEMES. página do Facebook. Criada em: 08 mar. 2018. Disponivel em: https://www.facebook.com/southprojetojaibamemes. Acesso em: 15 out. 2020. 
TROIAN, Alessandra; BREITENBACH, Raquel. Jovens e juventudes em estudos rurais do Brasil. Interações (Campo Grande), v. 19, n. 4, p. 789-802, 2018. Disponível em: https://doi.org/10.20435/inter.v19i4.1768. Acesso em: 22 nov. 2020.

WEISHEIMER, Nilson. Juventudes Rurais: mapa de estudos recentes. Brasília: Ministério do Desenvolvimento Agrário, 2005. Disponível em: http://atividaderural.com.br/artigos/568ba7c7c3acf.pdf. Acesso em: 28 nov. 2020.

WHITAKER, Dulce Consuelo Andreatta; ONOFRE, Silvana Aparecida. Representações sociais em formação sobre os vestibulares dos estudantes de um cursinho comunitário na zona rural. Revista Brasileira de Orientação Profissional, v. 7, n. 1, p. 45-55, 2006. Disponivel em: https://www.redalyc. org/articulo.oa?id=203016899006. Acesso em 16 jan. 2021.

\section{Notas}

1 Mestre em Extensão Rural Pela Universidade Federal de Viçosa, Doutoranda do Programa de Pós-graduação em Extensão Rural da Universidade Federal de Viçosa, Brasil. ORCID: 0000-0001-9959-3114.E-mail:angelina.melo@ufv.br

2 Doutora pelo Programa de Ingeniería para el Desarrollo Rural na Universidad de Santiago de Compostela. Professora adjunta da Universidade Federal de Viçosa, Brasil. ORCID: 0000-0001-6630-796X. E-mail: nathaliacosmo@ufv.br

3 Doutora em Antropologia Social pela Universidade de São Paulo. Professora Associada IV da Universidade Federal de Viçosa, Brasil. ORCID: 0000-0003-03109055. E-mail: sheila@ufv.br

4 "A mídia social é um grupo de aplicativos baseados na Internet que se apoiam nos fundamentos ideológicos e tecnológicos da Web 2.0 e permitem a criação e a troca de conteúdo gerado pelo usuário" (KAPLAN; HAENLEIN, 2010 p. 61, tradução própria). A Web. 2.0 referida pelos autores é uma plataforma da internet que possibilita que os seus usuários façam mais que usufruir, eles podem contribuir continuamente com a criação de conteúdo e modificações. Como exemplo de mídias sociais online tem-se o Facebook, Instagram, Twitter, Youtube, entre outros. Essas mídias possibilitam o compartilhamento de opiniões, textos, fotos, vídeos, imagens, entre outros conteúdos. 